\title{
El obsequio de tejidos como gesto de munificencia en el tardomedievo castellano: testimonios literarios
}

\author{
Sila OREJA ANDRÉS \\ Licenciada en Historia del Arte, Universidad Complutense de Madrid \\ Máster en Historia del Arte: Conocimiento y Tutela del Patrimonio Histórico, Universidad de Granada \\ iduna_sila@hotmail.com
}

\begin{abstract}
Resumen
La generosidad destaca como virtud inherente a la condición de reyes y nobles, y es por ello que el obsequio de regalos ha sido lugar común de los ambientes cortesanos a lo largo de la historia. En este sentido, durante el s. XV abundan las referencias literarias -sobre todo del género cronístico, especialmente minucioso en las descripciones- en las que el textil sobresale como objeto suntuario por excelencia para hacer públicos estos gestos de prodigalidad. El presente artículo compila algunos fragmentos de literatura coetánea al periodo escogido en los que queda evidenciado cómo el regalo de ricos paños vehicula mensajes sociales tales como el prestigio, la diplomacia, el altruismo o incluso el amor.
\end{abstract}

Palabras clave: Textil, dadivosidad, regalo, s. XV, Castilla, literatura, crónica.

\section{The Gift of Textiles as a Gesture of Munificence in Late Medieval Casti- le: Literary Testimonies}

\begin{abstract}
Generosity stands out as a presumed royal and noble virtue, and that is why giving presents has been a frequent habit throughout history. In this sense, $15^{\text {th }}$ century literature -especially chronicles, because of its detailed descriptions - is full of references to textile as the favorite sumptuary object to boast about this munificence. Thus, this paper compiles some contemporary literature extracts which give clear proof of the importance of textile gifts as a vehicle of messages such as prestige, diplomacy, altruism or even love.
\end{abstract}

Key words: Textile, generosity, gift, $15^{\text {th }}$ century, Castile, literature, chronicle. 
"Un rrey amando las cosas del mundo fizo cobrir el suelo de su palaçio e los asentamientos e las paredes de cortinas muy preciosas, e mando adereçar la mesa de rricos manteles e de vasos de oro e de plata. E entre los otros convidados que tenían convidara a un sabio, el qual estando asentado a la mesa del rrey, acato a todas partes onde podría escopir. E veyendo estar todo cobierto de tan preciossos ornamentos, escopio en la barba del rrey.

E luego los servientes travaron del. El rrey entendiendo que non sin caussa alguna el sabio feziera aquello, non consentio que le feziessen enojo, e preguntole por que feziera aquello. El rrespondio que acatando las cortinas e los vasos tan fermossos, non vio otro lugar mas vil e suzio que la barba del rrey que estaba llena de grosura de los manjares e por esso escopiera en ella" ${ }^{1}$.

El arte del tejido, disciplina de las bellas artes con pleno derecho ${ }^{2}$, gozó en el s. $\mathrm{XV}$ de una consideración mayor que las obras de pincel $^{3}$, puesto que lo que interesaba del arte no eran sus cualidades técnicas y estéticas, sino la singularidad de los materiales ${ }^{4}$.

Así, huyendo de un análisis basado únicamente en criterios decorativos, que darían al arte textil el valor de un producto meramente artesano ${ }^{5}$, la evaluación del arte del tejido responde simultáneamente a dos planos de la realidad. Por un lado, a su estimación como objeto valioso desde el punto de vista económico y estético, y por otro a su trascendencia simbólica como arte suntuaria, es decir, la proyección social que su uso implicaba a los individuos de las clases más acomodadas.

La lectura de las fuentes literarias de este periodo final de la Edad Media castellana brinda numerosas citas que nos aproximan al pensamiento medieval respecto al arte textil. Este, más allá de las puras cuestiones funcionales, se descubre como auténtica fuente de riqueza, asociada a la magnificencia y ostentación que caracterizó a los monarcas y sus cortesanos, y que los llevó, de una parte, a atesorar objetos valiosos, como fin en sí mismo, y de otra, a mostrar públicamente sus ricas pertenencias $^{6}$.

El material textil, dada esa elevada cotización, se presentó como recurso óptimo del aparato de ostentación regio y nobiliario ya que en la calidad del tejido residía la auténtica vara de medición de la holgura económica de cada miembro de la sociedad.

1 SÁNCHEZ DE VERCIAL, Libro de los exemplos por a.b.c., C. KELLER (ed.), Madrid, 1961, p. 151.

2 G. DELMARCEL, La tapisserie flamande $d u X^{e}$ au XVIII ${ }^{e}$ siècle, Tielt, 1999, p. 7.

3 M.A. ZALAMA RODRÍGUEZ, "La infructuosa venta en almoneda de las pinturas de Isabel la Católica", Boletín del Seminario de Arte y Arqueología (Arte), LXXIV (2008), pp. 45-66, y "Primacía de los tapices entre las artes figurativas en España en los siglos XV y XVI", F. CHECA CREMADES y B.J. GARCÍA GARCÍA (coords.), Los Triunfos de Aracne. Tapices flamencos de los Austrias en el Renacimiento, Madrid, 2011, pp. 17-36.

4 M.A. ZALAMA RODRÍGUEZ, "Tapices en los tesoros de Juan II y Enrique IV de Castilla: su fortuna posterior", J.M. PARRADO DEL OLMO (coord.), Estudios de historia del arte: homenaje al profesor de la Plaza Santiago, Valladolid, 2009, p. 57.

5 V. RAMÍREZ RUIZ, Las tapicerías en las colecciones de la nobleza española del siglo XVII, Madrid, 2013, p. 75.

6 M.A. ZALAMA RODRÍGUEZ, op. cit., 2009, p. 57. 
"E toma primero figura de sierpe de muchas pintada colores, trayendo en la boca venino. Esto faze el mundo mostrando las sus prosperidades e plazeres, siquiere bienandanças, que son entendidas por la variedat de las colores que a manera de prado de flores guarnesçido o de labores en paño de sirgo fermosas compone la piel de la engañosa sierpe, tincta de bivas e plazenteras de ver verduras, afalagando la vista. E de otra parte trae en la boca el peligroso escondido venino de viçios e penalidades, que procura a los que se reposan o confían en los sus delites"?.

En este pasaje de Los doce trabajos de Hércules dedicado a la lucha de Hércules con el gigante Atheleo, por el amor de Deamira - historia narrada por Ovidio en el noveno libro de Las Metamorfosis ${ }^{8}$, Villena añade una alegoría de los deleites sensoriales de la vida, en la que el tejido aparece como plasmación visual de esa belleza y exuberancia. Esto, independientemente de la moraleja extraída, es apto para advertir hasta qué nivel el arte textil era apreciado como auténtico arquetipo de finura y sublimidad estética, sinónimo de la vida como imagen magníficamente efímera.

La plasmación fáctica de esta reflexión teórica no es otra que la realidad de una sociedad tendente a calibrar su estructura jerárquica mediante estos sistemas de representación simbólica, un imperio de la apariencia en el que, como en casi todas las épocas, la máxima sería el tanto tienes, tanto eres.

La literatura no fue ajena a la introducción de la riqueza material como epíteto en la descripción y enjuiciamiento de los diversos individuos de la sociedad, por lo que son frecuentes las alusiones a estas artes del tejido como atributo de riqueza y distinción, ya sea en vestimenta o en tejido de ornamentación:

"Los que solíen ser gente mexilla son en estado que comen gallynas, beven con plata é tienen cortynas, e ya menos preçian blanquesa é palmilla"9

Es más, podríamos decir incluso que, en sí mismo, el tejido porta una carga simbólica que lo convierte en efigie del poder, tal y como se puede comprobar con el uso de los pendones ${ }^{10} \mathrm{o}$ en la elección de los tejidos para la confección de las vestimentas. En el Doctrinal de los Cavalleros, Cartagena efectúa una recomendación muy al caso de esta cuestión, al abordar el modo en que se han de repartir los objetos obtenidos del saqueo de villas y castillos en los que se entra por fuerza, y cuáles han de ser entregados a la autoridad regia:

7 ENRIQUE DE VILLENA, Obras completas. Los doce trabajos de Hércules, P.M. CÁTEDRA (ed.), Madrid, 1994, p. 60.

8 PUBLIO OVIDIO NASÓN, Las Metamorfosis, A. RAMÍREZ DE VERGUER y F. NAVARRO ANTOLÍN (trads.), Madrid, 2011.

9 Versos de Alfonso Álvarez de Villa Sandino extraídos de JUAN ALFONSO DE BAENA, El cancionero de Juan Alfonso de Baena (siglo XV), Buenos Aires, 1949, p. 95.

10 Respecto al valor simbólico de los pendones, aunque aplicando algunas de las conclusiones al caso castellano, destaca M.T. PÉREZ HIGUERA, Objetos e imágenes de Al-Andalus, Barcelona-Madrid, 1994. 
"entonce deven dar al rey su quinto de todas las cosas muebles que i ganasen, fueras ende de aquellas que fuesen tajadas con tiseras e cosidas con aguja. Y esto pusieron los antiguos por nobleza del rey, porque non tovieron que le convenía vestir paños que para otros fuesen començados o fechos" 11 .

En definitiva, el tejido como materia artística fue considerado en la Edad Media bien de absoluta valía pecuniaria y emblemática, conductora de todo un programa de códigos de significación que hacen de este arte suntuaria objeto de interés, no solo artístico -en el plano técnico y formal del término-, sino, y sobre todo, sociológico.

\section{Regalos y dones: el tejido como presente}

Junto a valores como el honor, la honra, la vergüenza, el valor o la fama, la generosidad se convierte en síntoma inequívoco de nobleza. La dadivosidad por la que se da sin esperar nada a cambio implica una actitud liberal, exigida a todo noble, y por ende, a todo rey, en tanto que cabeza representativa del sistema de valores de una sociedad. De hecho, la élite desprecia la avaricia y la codicia, propias de aquellos que valoran lo ganado como fruto de un esfuerzo nunca bien remunerado y expuesto a la constante rapiña de los poderosos ${ }^{12}$.

Así pues, se percibe en el tejido, objeto fundamental de estas actitudes de munificencia, por un lado, y mano izquierda social y política, por otro, y así lo expresó François Salet, reforzando asimismo la importancia del arte textil como atributo de prestigio:

"Reserva de capital y motor de la actividad económica, reserva de obsequios y de ornamentación, y arma, no carente de filo, de la diplomacia, la tapicería era además -junto con la orfebrería - un medio para afirmar el rango o la riqueza y, por consiguiente, para hacer tangible el poderío de los príncipes" ${ }^{\prime 13}$.

El empleo del arte del tejido como refuerzo del poder y la influencia de la aristocracia puso de moda el obsequio de piezas textiles a vasallos, reyes, a las damas como muestra de amor o, dado su alto coste, como parte de las dotes ${ }^{14}$.

Rasgos característicos del textil, como su fácil transporte, lo convirtieron en un bien suntuario ideal para ser regalado ${ }^{15}$. El tipo de tejido también influyó en su idoneidad para ello. La seda, por su extraordinario coste económico, fue el tejido predilecto para este tipo de actos de desprendimiento ${ }^{16}$, aunque también fue frecuente el uso de la lana

\footnotetext{
11 ALONSO DE CARTAGENA, Doctrinal de los cavalleros, J.M. VIÑA LISTA (ed.), Santiago de Compostela, 1995, p. 125.

12 V.M. GIBELLO BRAVO, La imagen de la nobleza castellana en la Baja Edad Media, Cáceres, 1999 , pp. 44-46.

13 La tapisserie française du Moyen Âge à nos jours: catalogue (Musée d'Art Moderne), París, 1946.

14 P. BARTY, Tapestry, Londres, 1994.

15 V. RAMÍREZ RUIZ, "Función de las tapicerías en la corte: siglo XVII", Res Mobilis: Revista internacional de investigación en mobiliario y objetos decorativos, 1 (2012), p. 24.

16 M.C. MARTÍNEZ MELÉNDEZ, Los nombres de tejidos en castellano medieval, Granada, 1989, p. 337.
} 
para tales fines, un paño decente, puro, de producción interior y carente de exotismo, que tanto valía para elaborar ajuar doméstico, como finos trajes, u otro tipo de prendas burdamente tratadas ${ }^{17}$.

Máxima expresión de ese concepto de dadivosidad es el encarnado por la figura del Condestable don Miguel Lucas de Iranzo, cuyo deseo de erigirse como perfecto señor quedó impecablemente expresado en su crónica, plagada de citas alusivas a sus hábitos altruistas y desprendidos:

"gastando quanto en el mundo tenía con todos, en entradas de tierra de moros, e convites, e colaçiones, e fiestas, e libreas, e dádiuas e merçedes de dineros e bestias e paños e sedas e joyas, a grandes e chicos, e adobando la torres e muros e pilares, las plaças e calles, carreras, caminos, según que ya es largamente contado"18.

Como vemos, se recurre a expresiones como "gastando quanto en el mundo tenía o mostró su acostunbrada magnanimidad e grandeza de corazón", valor moral propio del monarca e imitado, como otros tantos gestos regios, por nobles como Don Miguel Lucas de Iranzo ${ }^{19}$. Así, la crónica sigue:

"A cuyas bodas (de unos criados), bien así como en todas las otras cosas que face, mostró su acostunbrada magnanimidad e grandeza de coraçón. $\mathrm{Ca}$, demás de a las mujeres de aquestos mandar dar muy ricos paños, así briales de seda con ropas e mantos e briales de muy finos paños, más conplidamente que en aquella tierra a mujeres de escuderos se solía dar, con todas las otras cosas de tocas e gorgueras, camisas, manillas, sortijas e otras joyas, que ninguna cosa fallesçió, antes dando algunas de más que dar no se acostumbrauan, a ello, así mesmo, avnque bien vestidos estauan, jubones de seda, e capas e sayos, con lo que a esto se requería, quiso que las onrras e fiestas de las bodas muy conplidamente se ficiesen" 20 .

Era frecuente que con motivo de la celebración de festejos, los nobles hicieran alarde de toda su generosidad, multiplicando sus gestos dadivosos, plasmados en el reparto prolífico de todo tipo de regalos, destacando entre los presentes incluidos los tejidos, como bienes de gran valor, simbólico y económico. Las redundantes descripciones festivas de la crónica del Condestable insisten en el derroche del noble, hecho que se repite constantemente, y que no viene sino a reforzar la idea de un señor espléndido y próspero $^{21}$ :

17 M.I. MONTOYA RAMÍREZ, "El simbolismo en las vestiduras medievales y sus lexicalizaciones", E. GARCÍA WIEDEMANN (ed.), Moda y sociedad: estudios sobre educación, lenguaje e historia del vestido, Granada, 1998, p. 435.

18 Hechos del Condestable Don Miguel Lucas de Iranzo: crónica del siglo XV, J. DE MATA CARRIAZO (ed.), Madrid, 1940, p. 117.

19 De hecho, parece ser que en el caso del Condestable la conocida maurofilia de su rey, Enrique IV, le llevaría a adoptar una imagen análoga en lo que respecta a la indumentaria, costumbres, arquitectura, etc. M. JÓDAR MENA, "El gusto por lo morisco como símbolo de identidad del poder: el caso del Condestable Iranzo en el reino de Jaén”, Revista de Antropología experimental, 12 (2012), p. 340.

20 J. DE MATA CARRIAZO (ed.), op. cit., 1940, p. 133.

21 Abundantes son las referencias a esta dadivosidad en A. GIMÉNEZ CRUZ, "Ceremonial y juegos de sociedad en la Corte del Condestable Miguel Lucas de Iranzo", Boletín del Instituto de Estudios Giennenses, 
"Porque en otros lugares, ante desto, es contado el modo y estilo que en las otras fiestas pasadas el dicho señor Condestable tenía, e todos sus actos, asaz largamente, no conviene más repetirlos. Saluo que, después de aver fecho muchas merçedes, e dando grandes estrenas de seda e paños e ropas e dineros e cauallos, e otras joyas, a grandes e chicos, así a los naturales de la dicha çibdad como a otros muchos que de diversas partes concurrían, en mayor cantidad que en ninguna de las otras fiestas pasadas" 22 .

Entre todas estas celebraciones destacan las bodas, que en el caso de Miguel Lucas alcanza cotas magníficas, representando uno de los episodios más dilatados y cuidados de toda la crónica, en el que no faltan las constantes menciones al textil como presente de primer orden:

"Pues ya de todos los otros estrangeros que a sus bodas vinieron, e tanbién los de su casa, ninguno quedó a quien no mandase dar quier cauallo, quier mula, quier brocado, quier seda o paño o dineros, o otras joyas e jaezes de la gineta. E allende de las otras limosnas que cada día suele facer en estas fiestas de su magnífico matrimonio, fizo muy muchas, así a yglesias e monesterios como a otras personas religiosas e de otros estados que lo avían bien menester.

Pues tronpetas, ministreles de duçaynas e cherimías, atabaleros, tanborinos e pandereteros, e locos e truhanes, tañedores de cuerda e otras personas de más actoridad, así como trobadores e otros que en tales fiestas e de semejantes señores de estado acostunbran e suelen reçebir, que en las dichas fiesta avían concurrido, ¿quien podría numerar las merçedes e dádiuas de jubones de seda e ropas de finos paños, e dineros, e otras cosas que le mandó dar? Que no pareçía sinó que avíen entrado algúnd lugar de enemigos, e lo avían puesto a saco mano ${ }^{23}$; así yua cada vno cargado" 24 .

Otras muchas fiestas también eran momento ideal para el dispendio de un noble capaz de gastar lo indescriptible en aras de la consolidación de una imagen pública impecable. Ejemplo de ello son los festejos navideños, en los que el Condestable no reparó en gastos para ataviar lo más dignamente posible a todos los miembros de su casa, permitiendo advertir de forma directa la importancia de la riqueza textil como recurso de propaganda social y política:

"Y començando en estas, porque son las primeras, e comienço e cabeça del año, después de aver mandado vestir de nueuo de muy finos paños e sedas no solamente todos los de su casa mas muchos de los caualleros e escuderos, regidores e jurados de la çibdad de Jahén, e fijos de aquellos, e fechas muchas merçedes e limosnas en cada vna dellas" 25 .

120 (1984), pp. 83-103.

22 J. DE MATA CARRIAZO (ed.), op. cit., 1940, p. 101.

23 El cronista aprovecha la mínima ocasión para incidir en las frecuentes recompensas materiales obtenidas tras el saqueo de enclaves fronterizos, quehacer bélico presumiblemente habitual que venía a enaltecer la figura del noble, y del cual obtendría jugosas rentas. A. GIMÉNEZ CRUZ, op. cit. (1984), p. 339.

24 J. DE MATA CARRIAZO (ed.), op. cit., 1940, p. 60.

25 Ibid., p. 153. 
A lo cual añade la relevancia del obsequio de piezas textiles en este tipo de actos, dado su alto coste económico:

"En las quales fiestas el dicho señor Condestable facía muchas merçedes e limosnas, e daua grandes aguinaldos de brocados y sedas y paños finos, y enriques y doblas e otras monedas y joyas, según dicho es" 26 .

Por su parte, los monarcas también se caracterizaron por una gran liberalidad, reflejando siempre en la literatura su constante disposición a ayudar a aquellos que en un momento dado pudieran necesitarla. Destaca el ejercicio de estas actitudes agasajadoras cuando los intereses políticos y sociales hacen acto de presencia, tal y como se aprecia en la intervención de Enrique IV en el encuentro del duque de Guiana con su hermano:

"E concordose vista de los dos hermanos, por consentimiento de las dos partes en quien entonçe paresçia el reyno estar partido. E la fabla entrellos duro poco espaçio, e lo que se pudo conosçer a los de la una parte e de la otra, fue que se partian con gesto alegre; y el rey mando dar al duque çierta suma de oro para socorro de sus necesidades, e çiertas pieças de seda e paño, de que todos los que vieron fueron alegres" ${ }^{27}$.

La generosidad de los soberanos solía prolongarse hasta el mismo momento de su fallecimiento, tal y como reseña la Crónica de Juan II, en la que se acompaña la disposición testamentaria de su padre, el rey Enrique III, que, una vez más, permite valorar la significación social del arte textil:

"Otrosí mando que las mis ropas de vestir de oro e seda, con sus forraduras, que están en la mi cámara, que los mis testamentarios ordenen dellas por mi ánima, ansí en ornamentos como en cosas piadosas e en otras cosas, segund que bien visto les fuere.

[...] Otrosí, mando que el día de mi enterramiento que den de vestir a seisçientos pobres, a los çiento a cada ocho varas de paño de color, e a los quinientos capas e sayos de sayal" 28 .

El hecho de la muerte brinda a ciertas personas y grupos la ocasión de hacer ostentación de su poder, al emplear los aspectos directamente relacionados con lo funerario como vehículo para hacer gala del prestigio del que eran portadores, y en este caso el carácter de munificencia que acompañó al personaje en su vida. Han de ser consideradas como fundamentales este tipo de mandas piadosas testamentarias, así como la pompa funeraria y la memoria de los difuntos, expresada esta última en el panteón familiar y en la fundación de capellanías ${ }^{29}$.

26 Ibid., p. 162.

27 Crónica anónima de Enrique IV de Castilla 1454-1474 (Crónica castellana), M.P. SÁNCHEZ-PARRA (ed.), Madrid, 1991, p. 91.

28 Crónica de Juan II de Castilla, J. DE MATA CARRIAZO (ed.), Madrid, 1982, p. 28.

29 J.R. PALENCIA HERREJÓN, "Elementos simbólicos de poder de la nobleza urbana en Castilla: los Ayala de Toledo al final del Medievo", En la España medieval, 18 (1995), p. 172. 
Pese a que en este estudio interesa el análisis de aquellos comportamientos en relación a los mecanismos de propaganda y representación simbólica de reyes y nobles, no pueden dejarse de lado ciertos detalles de tinte más cotidiano que nos ayuden a matizar la importancia que el textil jugó en la mentalidad del s. XV castellano. Los tejidos no solo fueron objeto de obsequio como vehículo político y social, sino que también eran regalo frecuente de tipo personal, como manifestación de sentimientos. Por ejemplo, de Enrique IV sabemos su afición a proveer de bienes preciosos a su amada doña Guiomar, a la cual colmó de regalos que llegaron a despertar la envidia de la propia reina ${ }^{30}$, y que desde el punto de vista histórico-artístico nos puede ayudar a reconstruir un posible universo femenino cortesano ${ }^{31}$ :

"Esta doña Guiomar fue una de las principales donzellas que la reyna doña Juana traxo de Portogal, a la qual el rey mostrava tan grande amor que ya paresçia tener en poco a la reyna. $\mathrm{E}$ tan grande era la privança que con el rey tenia, que qualquiera merçed que alguno quería aver del rey no lo procurava salvo por la mano de doña Guimar; la qual ya tenia tan grant parte en el que ninguna cossa le denegava que quanto por ella le era demandado, a cabsa de lo qual era tan servida e tan acatada e tan grandes presentes le fazian de oro e de piedras e perlas e sedas, que prestamente fue tan rica e tan enjoyada que era una cossa maravillossa, de que la reyna avia tan grande enojo e tenia tan gran çelo quanto de razón tener devia, segund el poco amor que ya el rey le mostrava, y la sobrada voluntad que en todo pareçie tener a doña Guiomar"32.

Regalar tejidos no era otra cosa que ofrecer importantes sumas de dinero a sus receptores $^{33}$, mostrándose aquí la cara más frívola de esta manifestación artística, como valor de mercado que es lo que caracterizó durante siglos al arte, el prestigio de una obra en función del importe de los materiales y la complejidad técnica de su proceso de creación. De este hecho, se puede recoger una noticia muy interesante en el viaje hecho por Jorge de Ehingen a mediados del s. XV a España y Portugal, en el que tras relatar las ceremonias con las que fue recibido por las Cortes de ambos países, explica los dones textiles recibidos y cómo, llegado a un punto del viaje, se desprendió de tales bienes para transformarlos en efectivo:

30 Del papel desempeñado por las amantes de Enrique IV y otros monarcas medievales, véase A. FIRPO, "Las concubinas reales en la Baja Edad Media castellana", Y.-R. FONQUERNE y A. ESTEBAN (coords.), La condición de la mujer en la Edad Media. Actas del coloquio celebrado en la Casa de Velázquez, Madrid, 1986, pp. 333-341, en concreto las páginas 340 y 341, en las que se especifica la relación que mantuvieron esta dama portuguesa y el soberano castellano.

31 F. CHECA CREMADES, "Fiestas, bodas y regalos de matrimonio", M.A. ZALAMA RODRÍGUEZ (dir.), Juana I en Tordesillas: su mundo, su entorno, Valladolid, 2010, pp. 135-162.

32 M.P. SÁNCHEZ-PARRA (ed.), op. cit., 1991, p. 84.

33 Solo para aproximarnos al valor pecuniario del tejido baste leer las relaciones de precios de diversas calidades textiles aportadas por Ladero Quesada en algunas de sus publicaciones como M.A. LADERO QUESADA, "Limosnas, dádivas y liberaciones en torno a la toma de Granada (1490-1492)", Revista del Centro de Estudios Históricos de Granada y su Reino, 24 (2012), pp. 31-33, y La armada de Flandes. Un episodio en la politica naval de los Reyes Católicos (1496-1497), Madrid, 2003, y Las Indias de Castilla en sus primeros años. Cuentas de la Casa de la Contratación. 1503-1521, Madrid, 2008. 


\begin{abstract}
“atravesamos por Portugal y por España, y cuando llegamos a una gran ciudad llamada Zaragoza, vendimos la tela bordada de oro y todo el terciopelo que no necesitábamos para nosotros, y ganamos 500 ducados" ${ }^{34}$.
\end{abstract}

Volviendo a la proyección política de este hábito del regalo textil, las embajadas supusieron una ocasión de especial relevancia en el aparato diplomático de las relaciones exteriores de los monarcas. Así, serían cuantiosos los fragmentos que podrían ser acompañados en este estudio, como ejemplo de la prodigalidad de la que Juan II y Enrique IV llegaron a alardear cuando se trataba de de sostener su prestigio gubernativo internacional.

Hacia el sur, destacan las relaciones con el Reino de Granada. Así, la embajada ordenada por el rey Ciriza ${ }^{35}$, en la que envió a su hijo a la Corte de Enrique IV, se dice:

"E luego que a Segovia llego, el rey lo resçivio muy graciosamente e mando bien aposentar a el e a todos los suyos y enbiole gran suma de doblas y çiertas pieças de seda e de finos paños, para vestir a el e a los prinçipales de su conpañia, y otras pieças de menores paños para vestir toda la otra gente común"36.

Asimismo, llegan noticias respecto a los contactos mantenidos con el norte de África:

"Dende as pocos días, estando el Rey allí en Valladolid, el día del fornazo, como lo él solía mandar fazer çada año, llegaron embaxadores del rrey de Túnez, con los quales le envió presentes de paños de seda moriscos, e chamelotes de seda, e perfumes.

E envió con ellos al rrey de Túnez çiertas pieças de escarlata, e seys mulas muy bien guarnidas" 37 .

Acerca del trato con las Cortes europeas, se conoce el mimo con el que se preparaba la recepción de los embajadores, como la del representante del duque de Bretaña, al que se agasajó con excelentes fiestas y presentes:

"Acabadas las fiestas y el enbaxador tratado con tanta honrra, dada con mucha conclusyón en su enbaxada, el rrey le mandó haser grandes merçedes de cavallos e mulas, plata e dineros, pieças de brocado y de seda, con que se partió muy contento, loando la grandeza de su estado" 38 .

34 J. GARCÍA MERCADAL (ed.), Viajes de extranjeros por España y Portugal: desde los tiempos más remotos hasta comienzos del siglo XX, Valladolid, 1999, p. 235.

35 Llamado así por las crónicas cristianas, es el rey granadino Abú Nasr Sa'd o Sidi Sa'd.

36 M.P. SÁNCHEZ-PARRA (ed.), op. cit., 1991, p. 24.

37 LOPE DE BARRIENTOS, Refundición de la Crónica del Halconero, J. DE MATA CARRIAZO (ed.), Madrid, 1946, p. 132.

38 DIEGO ENRÍQUEZ DEL CASTILLO, Diego, Crónica de Enrique IV, A. SÁNCHEZ MARTÍN (ed.), Valladolid, 1994, p. 169. 
La merced regia de productos textiles era especialmente valorada al simbolizar en cierto grado un vínculo especial de confianza entre el donante y el beneficiario ${ }^{39}$, de hecho, en ocasiones, el contacto fue directo entre los monarcas, y no a través de delegados, enfatizándose la necesidad de complacer al visitante con el regalo de ricas piezas de tejido y otros actos de homenaje y entusiasmo:

"E quando al rrey de Armenia dixieron: "Señor, he allí el rrey do viene, donde aquella espada viene alçada," entonces el rrey de Armenia de lexos apeose de la mula e finco los jnojos en tierra e espero al rrey llorando. E el rrey don Juan, desque le vido en esta manera, apeose el e todos los suyos, e vino al rrey, e alçole de tierra, e estaua el rrey de Armenia dando bozes: "Bien, venga mi sseñor, poderoso prinçipe de Castilla, temido allende la mar, que me rredimio de poder de los jnfieles de nustra fee!" E queriale besar las manos, tanto que todos llorauan; e en esto abraçaronse, e dieronse paz, e vinieron con mucha alegría a Badajoz. E luego el rrey le dio muchos paños de oro e vasijas de plata, e diole a Madrid por su vida, e Andujar con todas las rrentas del rrey, e mas çinquenta mill marauedis cada año para su costa. E ouo el rrey dos cartas, vna del soldan, e otra de su alguacil mayor" ${ }^{\prime 4}$.

Por último, el tejido como bien de lujo sirvió con frecuencia de trofeo de torneos, justas y todo tipo de juegos de caballería, festejos en los que la ostentación textil era fundamental al implicar, tal y como indica Rosana de Andrés, "gasto, regalos, generosidad, ahorro, intercambios, hospitalidad, movilidad de bienes, ostentación, derroche, rivalidad económica y otras actitudes económicas" ${ }^{41}$.

Con motivo de la recién señalada visita del embajador del duque de Bretaña, Enrique IV organizó aparatosas celebraciones narradas de la siguiente manera por Enríquez del Castillo:

"La fiesta duró quatro días: En el primero, se hiso vna justa de veynte cavalleros, diez de cada parte, todos con muy rricos paramentos y ataviados, yva preçio de vna pieça de brocado e otras dos de carmesy terçiopelo para los que mejor lo fisiesen. El segundo día, corrieron toros e después vn juego de cañas, en que avia çient cavalleros, çinquenta por çinquenta, los más prinçipales nobles hijos de grandes que avia en la corte, todos con jaheses dorados y grandes atavíos de sus personas. El terçero, fue de vna señalada montería, donde se mataron muchos bravos e peligrosos, asy a cavallo como a pie. Par estas fiestas hiso el rrey muchas merçedes de dineros, brocados, sedas, paño y syngulares enforros de martas, ermiños, grises y veros, no solamente a la rreyna y a sus damas y a los prinçipales señores de su corte mas a sus criados e servidores e a los otros nobles cavalleros que lo seguían"42.

39 M.A. LADERO QUESADA, op. cit. (2012), pp. 31-33.

40 ALFONSO MARTÍNEZ DE TOLEDO (Arcipreste de Talavera), Atalaya de las Crónicas, J.B. LARKIN (ed.), Madison, 1983, p. 106.

41 R. DE ANDRES DÍAS, "Las fiestas de caballería en la Castilla de los Trastámara", En la España medieval, 8 (1986), pp. 81-108.

42 DIEGO ENRIQUEZ DEL CASTILLO, op. cit., 1994, p. 169. 
El Condestable don Miguel Lucas no fue menos cuando de premiar a sus caballeros se trataba:

"E así por más ynçitallos a ello como porque siempre buscaua ynvençiones en que les ficiese merçedes y les diese de lo suyo, cada día que avían de jugar a las cañas mandaua poner de su cámara çiertas joyas; conviene a saber, camisas moriscas, e tocas tuneçís, e gentiles almaysares, e capirotes moriscos, de muy finos paños, bien fechos borceguís marroquíes" ${ }^{43}$.

Los monarcas se preocuparon por ataviar ricamente a los caballeros, miembros representativos del engranaje social bajomedieval que se caracterizaron por una gran riqueza en su atavío, favorecida en ocasiones por la bondad de su rey:

"En este mes de setiembre e año suso escripto, fizo el Rey su condestable a su criado Álbaro de Luna, estando en Tordesyllas, con muchas çerimonias. Este condestable dió muchas dádibas de caballos, e muchas rropas, a todos los caballeros que a la sazón ally estaba. Este día dio el Rey muchas rropas de azeytuný brocado, e muchas rropas de seda e de lana forradas en martas, a todos los de su cassa, e muchas joyas. E fizo justar a estos cavalleros de su cassa" ${ }^{44}$.

Como recapitulación del empleo del tejido como regalo de tipo personal, político y social por parte de las clases más acomodadas, se puede analizar un fragmento de El Victorial en el que se aúnan la generosidad, en este caso del monarca, hacia sus caballeros y miembros de su Corte y el deseo de ostentación ante ojos foráneos:

"El rey don Enrique era magnánimo e muy cathólico, e honrava mucho las iglesias e las fiestas de Dios, e de Santa María, e de los Apóstoles, e de los otros santos. Cuando mandava hazer muy honradas fiestas e proçisiones, mandava hazer justas e torneos e juegos de cañas, e dava armas e cavallos e ricas ropas e guarniçiones a aquellos que estas cosas avían de fazer, espeçialmente cuando benían a su corte embajadores extranjeros de otros reinos" ${ }^{\prime 5}$.

\section{Conclusiones}

Dadas las circunstancias sociopolíticas, las altas jerarquías sociales de la Baja Edad Media castellana hubieron de perfeccionar sus estrategias de sociabilidad. Así, la práctica del regalo materializó el esplendor y acumulación de virtudes propios de un estamento que ha de presentarse como modelo del comportamiento humano ${ }^{46}$.

\footnotetext{
43 J. DE MATA CARRIAZO (ed.), op. cit., 1940, p. 116.

44 PEDRO CARRILLO DE HUETE, Crónica del halconero de Juan II, J. DE MATA CARRIAZO (ed.), Granada, 2006, p. 9.

45 GUTIERRE DÍEZ DE GAMES, El Victorial, vida de Pero Niño, A. MIRANDA (ed.), Madrid, 1993, p. 283.

46 L. SUÁREZ FERNÁNDEZ, "Nobleza y monarquía: sus interrelaciones", VI Congreso de Estudios Medievales. La nobleza peninsular en la Edad Media, León, 1997, p. 481.
} 
En este sentido, el arte textil se convirtió en material predilecto de esta dadivosidad, dada su finura técnica, belleza estética y sobre todo por su carácter portátil y alto coste económico, práctico en su utilidad inmediata, pero también apreciado por las futuras posibilidades especulativas que ofrecía.

Asimismo, la literatura nos ayuda a dilucidar los episodios concretos en los que la ofrenda de tejidos constituye un ejemplo de magnanimidad noble y regia, y permite, igualmente, conocer la terminología empleada en unos relatos generalmente marcados por una fuerte carga propagandística.

Por todo ello, podemos considerar el legado literario como una fuente de gran valor para analizar el arte textil en relación a sus funciones sociales y no solo sus posibilidades estéticas y decorativas. 